\title{
Study of Missing Clinical Details in Computed Tomography Radiology Request Forms: A Descriptive Cross-sectional Study
}

\author{
Muna Badu' \\ 'Department of Radiology, Kathmandu Medical College and Teaching Hospital, Sinamangal, Kathmandu.
}

\section{ABSTRACT}

Introduction: Detailed clinical history through a properly filled requisition form can help a radiologist in making a diagnosis. The objective of this study was to observe the missing clinical details of Computed Tomography requisition forms at radiology department in tertiary care hospital.

Methods: This descriptive cross-sectional study was done in 196 Computed Tomography requisition forms in the department of radiology from September 2019 to October 2019. Ethical clearance from the Institutional Review Committee - Reference No. 120720194 was obtained. An informed consent from the participants was taken prior to the procedure. Convenient sampling was done. The data obtained were computed and analyzed using Statistical Package for Social Sciences to tabulate the results. The results were displayed in frequency and proportion of binary data.

Results: All the request forms had name filled, however date was filled in $183(93.4 \%)$, age was filled in 195 (99.5\%), sex was filled in 193 (98.5\%) and address was only in 30 (15.3\%) of the forms. Clinical history and provisional diagnosis were written in 179 (91.3\%) forms. Signature was found in more than half of forms 135 (68.9\%) whereas the department referring the patient was filled in $92(46.9 \%)$ of forms and the name of doctor referring the patient was not filled mostly. The handwriting was clear in $191(97.4 \%)$ of cases and standard words were used. Use of non-standard abbreviation was found in only 2 (1\%) forms.

Conclusions: Clinical details were filled in most of the requisition forms however other parameters were still incompletely and inadequately filled.

Keywords: data; forms; missing; Tomography; radiology.

\section{INTRODUCTION}

Radiologists report informally that missing clinical information is a daily occurrence and is a constant source of irritation and delay in giving computed tomography (CT) reports. ${ }^{1} \mathrm{~A}$ radiologist helps in making a diagnosis. This can only be achieved if the clinicians give a detailed clinical history through a properly filled request form. These are documented requests filled by clinicians with demographic details, clinical history, provisional diagnosis and referring physician's signature. ${ }^{2}$

Complete filling of the forms is important for radiologists to give concise diagnosis and avoid unhelpful

Correspondence: Dr. Muna Badu, Department of Radiology, Kathmandu Medical College and Teaching Hospital, Sinamangal, Kathmandu, Nepal. Email: muna.badusimkhada@gmail.com, Phone: +977-9851075682. 
examinations and radiation exposure. ${ }^{3}$ Inadequate information can reduce the value of the report and leading to a mistake in patient identification and delay in returning reports to correct destination. ${ }^{4}$

The objective of this study was to find out the prevalence of adequate filling of request forms of CT scans in radiology department of Kathmandu Medical College and Teaching Hospital.

\section{METHODS}

This descriptive cross-sectional study was carried out on CT requisition forms from September 2019 to October 2019 in the department of radiology of Kathmandu Medical College and Teaching Hospital. Ethical clearance from the Institutional Review Committee - Reference No. 120720194 was obtained. Informed consent of the participants was taken prior to the procedure. All the details in the requisition forms were recorded. All the CT scan forms were included for study. Patients who did not give consent were not included in this study. Convenient sampling was done and the sample size was calculated with prevalence $50 \%$.

The sample size $(n)$ was calculated as follows:

$\mathrm{n}=\mathrm{Z}^{2} \times \mathrm{p} \times \mathrm{q} / \mathrm{e}^{2}$

$=(1.96)^{2} \times 0.5 \times 0.5 /(0.07)^{2}$

$=196$

Where,

$\mathrm{n}=$ Sample size

$Z=1.96$ for $95 \%$ confidence interval

$\mathrm{p}=$ prevalence $(50 \%)$

$q=1-p$

$\mathrm{e}=$ margin of error, $7 \%$

Hence, the total sample size taken was 196.

The data obtained were computed and analyzed using SPSS to tabulate the results. The results were displayed in frequency and proportion of binary data.

\section{RESULTS}

A total of 196 CT request forms were studied for their completion. All the request forms had name filled, however date was filled in $183(93.4 \%)$, age was filled in 195 (99.5\%), sex was filled in 193 (98.5\%) and address was only in $30(15.3 \%)$ of the forms (Table 1$)$.

\begin{tabular}{|lll|}
\hline Table & 1. Demographic profile. \\
\hline S.N. & Variables & $\mathbf{n ~ ( \% )}$ \\
1. & Date & $183(93.4)$ \\
2. & Patient's Name & $196(100)$
\end{tabular}

\begin{tabular}{|lll|} 
3. & Age & $195(99.5)$ \\
4. & Sex & $193(98.5)$ \\
5. & Address & $30(15.3)$ \\
\hline
\end{tabular}

Clinical history and provisional diagnosis were written in 179 (91.3\%) forms and it was missing in 17 (8.67\%) requisition forms (Figure 1 ).

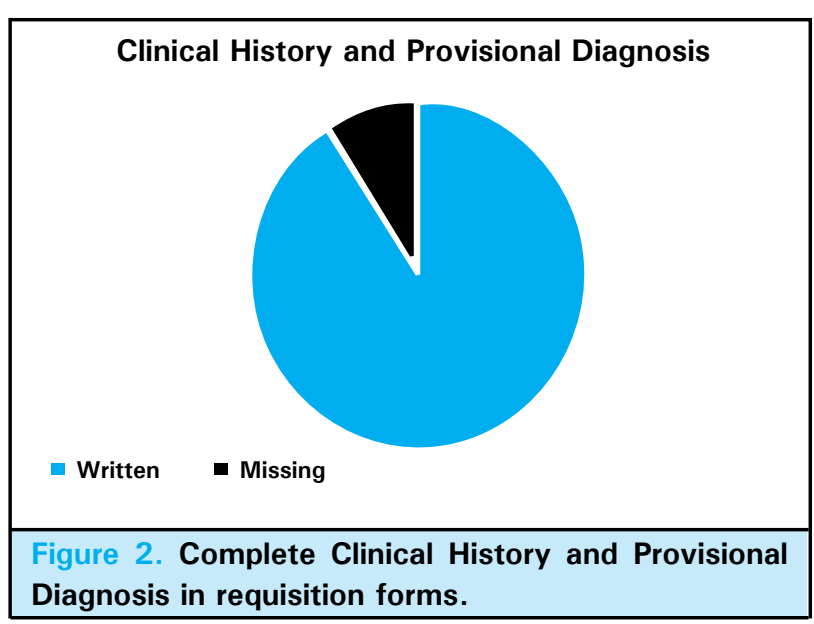

Signature was found in more than half of forms 135 $(68.9 \%)$ whereas the department referring the patient was filled in 92 (46.9\%) of forms and the name of doctor referring the patient was not filled mostly (Table 2).

\begin{tabular}{|lll|}
\hline \multicolumn{2}{|l|}{ Table 2. } & Referral details. \\
\hline S.N. & Referral details & $\mathbf{n ~ ( \% )}$ \\
1. & Referred by & $60(30.6)$ \\
2. & Department & $92(46.9)$ \\
3. & Signature & $135(68.9)$ \\
\hline
\end{tabular}

The handwriting was clear in 191 (97.4\%) of cases and standard words were used. Use of non-standard abbreviation was found in only $2(1 \%)$ forms (Table 3$)$.

\begin{tabular}{|lll|}
\hline \multicolumn{2}{|l|}{$\begin{array}{l}\text { Table } \\
\text { with } \\
\text { abbreviations. }\end{array}$} & $\mathbf{n}(\%)$ \\
\hline S.N. number and percentage of request forms & Variables & handwriting and non-standard \\
1. & $\begin{array}{l}\text { Legibility } \\
\text { handwriting }\end{array}$ & $191(97.4)$ \\
2. & $\begin{array}{l}\text { Use of non-standard } \\
\text { abbreviation }\end{array}$ & $2(1)$ \\
\hline
\end{tabular}




\section{DISCUSSION}

The radiology requisition forms are usually the only means of communication between clinician and radiologists. ${ }^{5}$ The opportunity to discuss cases between clinician and radiologist is not always possible. Whenever necessary, additional information can be acquired by radiologist by contacting patient or referring physician. ${ }^{6}$

Incomplete filling of radiology request forms is a worldwide problem. ${ }^{7}$ The Royal College of Radiologists clearly suggested that all radiology request forms should be adequately and legibly completed to avoid any misunderstanding of the request. ${ }^{8}$ The level of information in radiology request forms reflect the quality of radiology reports. ${ }^{9}$

Inadequate information in demographic details may affect in identification of the patient. Patient name was filled in all cases $(100 \%)$ which is similar to studies done by Anjum et al, Afolabi et al and Irurhe et al. ${ }^{3,7,10}$ Date was filled in $93.4 \%$ of cases which is close to study done by Afolabi et al and Irurhe et al. ${ }^{7,10}$ Age of the patient was filled in $99.5 \%$ of cases which is similar to observation made by Akinola et al. and Irurhe et al. ${ }^{6,10}$ However Jumah et al. found that the age of the patient was not filled mostly. ${ }^{11}$ Sex was mentioned in $98.5 \%$ of cases which is close to studies done by Irurhe et al. and higher than in study by Anjum et al. 3,10 Address was filled only in $15.3 \%$ of forms in my study which is close to study done by Irurhe et al, Afolabi et al. and Anjum et al. $3,7,10$

Clinical details are one of the most important part of the radiology request forms. Inadequate and missing clinical details may lead to inaccurate report while accurate clinical information help radiologist in making a report which may be more helpful to referring doctor and patient management. ${ }^{6}$ In my study clinical details were filled in $91.3 \%$ of cases which is similar to studies done by Akinola et al and Irurhe et al. ${ }^{6,10}$ In studies done by
Afolabi et al, Abbas et al and Jumah et al clinical details were inadequate. ${ }^{7,12,13}$

The name of the referral doctor, referral department and signature of the doctor were found in $30.6 \%, 46.9 \%$ and $68.9 \%$ of request forms respectively. This finding is lower compared to observation made by Abbas et al. and Irurhe et al. ${ }^{10,12}$

Illegible handwriting and use of non-standard abbreviations were found in $2.6 \%$ and $1 \%$ of cases. This finding is least common compared to previous studies by Akintomide et al, Rao and Jumah et al. ${ }^{11,13,14}$

The observation of missing clinical details in CT requisitions had different results in different studies. Some found it be less while other found it be high. Most of the requisition forms in my study had clinical details written on it with legible handwriting and very less use of non-standard abbreviations.

The sample size was small in this study which might make the results less generalizable. Information like last menstrual period, renal function tests, allergic history and current usage of drugs like metformin are very important factors for consideration for CT scan which were missing in the requisition form of our hospital.

\section{CONCLUSIONS}

Clinical details were filled in most of the requisition forms however other parameters were still incompletely and inadequately filled.

\section{ACKNOWLEDGEMENTS}

I would like to thank all the staff of department of Radiology.

Conflict of Interest: None.

\section{REFERENCES}

1. Burnett SJ, Deelchand V, Franklin BD, Moorthy K, Vincent C. Missing clinical information in NHS hospital outpatient clinics: prevalence, causes and effects on patient care. BMC Health Serv Res. 2011 May 23;11:114. [PubMed | Full Text I DOI]

2. Zafar U, Abid A, Ahmad B, Ahmad HA, Zafar F, Baig F, et al. Adequacy of completion of computed tomography scan request forms at a tertiary care center in Pakistan: a clinical audit. Cureus. 2018 Oct 20;10(10):e3470. [ $\underline{\text { PubMed I Full Text }}$ I DOI]

3. Anjum $\mathrm{H}$, Ahmad $\mathrm{H}$. Are the $\mathrm{CT}$ scan request forms adequately filled? Pakistan Journal of Radiology. 2016;26(3):179-82. [Full Text]

4. Teunen D. The European directive on health protection of individuals against the dangers of ionising radiation in relation to medical exposures (97/43/EURATOM). J Radiol Prot. 1998 Jun;18(2):133-7. [ [PubMed | Full Text | DOI]

5. Akinola R, Akinkunmi M, Wright K, Orogbemi O. Radiology request forms: are they adequately filled by clinicians? The Internet Journal of Radiology. 2009;12(1). [Full Text]

6. Afolabi OA, Fadare JO, Essien EM. Audit of completion of 
radiology request form in a Nigerian specialist hospital. Ann Ib Postgrad Med. 2012 Dec;10(2):48-52. [PubMed | Full Text]

7. Depasquale R, Crockford MP. Are radiology request forms adequately filled in? An audit assessing local practice. Malta Medical Journal. 2005 Nov;17(4):36-8. [Full Text]

8. Oyedeji OA, Oqbenna AA, Iwuala SO. An audit of reques $\mathrm{t}$ forms submitted in a multidisciplinary diagnostic center in Lagos. Pan Afr Med J. 2015 Apr 29;20:423. [PubMed | Full $\underline{\text { Text }} \mid \underline{\mathrm{DOI}}]$

9. Cook PG, Birchall IW, Jeans WD. Audit of quality in a radiological department--a pilot study. Clin Radiol. 1991 Nov;44(5):345-9. [PubMed | Full Text | DOI]

10. Irurhe NK, Sulaymon FA, Olowoyeye OA, Adeyomoye AA. Compliance rate of adequate filling of radiology request forms in a Lagos university teaching hospital. World Journal of Medical Sciences. 2012;7:10-2. [Full Text]
11. Akintomide AO, Ikpeme AA, Ngaji AI, Ani NE, Udofia AT. An audit of the completion of radiology request forms and the request practice. J Family Med Prim Care. 2015 Jul-Sep;4(3):328-30. [PubMed | Full Text | DOI]

12. Abbas M, Omer A, Hamad M. Adequacy of clinical information on radiology request cards from medical assessment unit-James Cook University Hospital, clinical audit. Nucl Med Biomed Imaging. 2016;1(1):5-6. [Full Text | DOI]

13. Jumah KB, Gordon-Harris L, Agahowa JI. Common faults in filling of the radiological request forms. East Afr Med J. 1995 Nov;72(11):744-5. [ubMed]

14. Rao VR. Audit of radiology request forms -"are they adequately filled?" Journal of Medical and Scientific Research. 2014 March;2:41-4. [Full Text] 